\title{
Completion time and performance on multiple-choice and essay tests
}

\author{
PAUL W. FOOS \\ Florida International University, North Miami, Florida
}

\begin{abstract}
The relationship between the order in which students completed multiple-choice or essay tests and their scores on those tests was examined; no significant relationship was found. One cannot successfully predict a student's test score by knowing when the student completed the test.
\end{abstract}

The relationship between the time that students take to complete a test and their score on that test has been examined a number of times. In most cases, time is measured by the order in which students complete the test (e.g., Burack, 1967; Johnson, 1977; Michael \& Michael, 1969; Paul \& Rosenkoetter, 1980), although some have measured actual time taken (e.g., Bridges, 1985; Terranova, 1972). All have used objective/recognition type tests (e.g., multiple-choice), and the results have been quite mixed.

Bridges (1985) and Burack (1967) failed to find any relationship at all. Michael and Michael (1969) found that students finishing in the middle obtained the highest scores, but they were later unable to replicate this finding. Johnson (1977) found that very high and very low scores occurred for those finishing first or last, while average scores occurred for those finishing in the middle. Paul and Rosenkoetter (1980) found highest scores for those finishing first, whereas Terranova (1972) found higher scores for those finishing in the middle. There appears to be no consistent relationship between test time and performance on multiple-choice tests.

The present research examines the relationship between test time, as measured by order of completion, and scores on a recall/essay test. This relationship, which has not yet been examined, may prove to be more stable than that found with multiple-choice tests (Bridges, 1985). The relationship between test time and scores on a multiple-choice test is also examined. In neither case was a significant relationship expected.

\section{METHOD}

\section{Participants}

The participants were 57 and 61 students enrolled in two sections of the same undergraduate psychology course at Florida International University.

\footnotetext{
Materials

One class (the 57 students) received a 40-item multiple-choice test during finals week; the other class (the 61 students) received a 5-item
}

Requests for reprints should be sent to Paul W. Foos, Department of Psychology, Florida International University, No. Miami, FL 33181.
Table 1

Mean Proportions Correct for Students Finishing in the First Through Fourth Quarters on Multiple-Choice and Essay Tests

\begin{tabular}{ccc}
\hline \multirow{2}{*}{$\begin{array}{c}\text { Quarter in which } \\
\text { Students Finished }\end{array}$} & \multicolumn{2}{c}{ Test Type } \\
\cline { 2 - 3 } & Multiple-Choice & Essay \\
\hline First & .69 & .84 \\
Second & .68 & .73 \\
Third & .76 & .86 \\
Fourth & .71 & .79 \\
\hline
\end{tabular}

essay test. Both tests covered the same material presented by the same instructor.

\section{Procedure}

The order in which students finished each test was marked on their final exams. The tests were scored by an individual who was unaware that data were being collected.

\section{RESULTS}

The correlations between order of completion and scores on the multiple choice and essay tests were not significant $[r(55)=.21$ and $r(59)=.05$, respectively]. Table 1 shows the average scores for students finishing in the first, second, third, and fourth quarters on both exams. To achieve an equal $n$ in each quarter, a random score was dropped from each test. An ANOVA was conducted, with quarter of completion serving as the independent variable for each test. There were no significant differences on multiple-choice or essay tests $[F(3,52)=$ 3.43 and $F(3,59)=1.35$, respectively].

\section{DISCUSSION}

No significant relationship was found between order of completion and scores on multiple-choice or essay tests. Although some others have found such a relationship, rarely have they found the same relationship. It seem fair to conclude that there is no stable relationship between order of completion and scores on multiple-choice tests and no relationship at all between order of completion and scores on an essay test. It is clear that one cannot predict test score from order of completion.

\section{REFERENCES}

BRIDGES, K. R. (1985). Test-completion speed: Its relationship to performance on three course-based objective examinations. Educational \& Psychological Measurement, 45, 29-35. 
BuRACK, B. (1967). Relationship between course examination scores and time taken to finish the examination, revisited. Psychological Reports, $20,164$.

Johnson, J. (1977). Exam-taking speed and grades. Teaching of Psychology, 4, 148-149.

Michael, J. J., \& Michael, W. B. (1969). The relationship of performance on objective achievement examinations to the order in which students complete them. Educational \& Psychological Measurement, 73, 511-513.
Paul, C. A., \& Rosenkoetter, J. S. (1980). The relationship between the time taken to complete an examination and the test score received. Teaching of Psychology, 7, 108-109.

Terranova, C. (1972). Relationship between test scores and test time. The Journal of Experimental Education, 40, 81-83.

(Manuscript received August 26, 1988.) 